\title{
Design of Multi-layer Anode for Direct Methanol Fuel Cell
}

\author{
Tsuneyoshi Nakashima, Hiroyuki Saito, Katahiro Murano, Choji Fukuhara, \\ and Masao SudoH*
}

Department of Materials Science and Chemical Engineering, Shizuoka University (3-5-1 Johoku, Naka-ku, Hamamatsu 432-8561, Japan)

\author{
Received October 28, 2010 ; Accepted January 13, 2011
}

\begin{abstract}
To improve the catalyst utilization and reduce the catalyst amount, we designed the anode structure. The superior catalyst utilization of direct methanol fuel cell (DMFC) was obtained by localized catalyst loading on the reaction sites. Hence the multi-layer anode with localized catalyst loading was prepared by the sputtering method. The designed multi-layer electrode showed a high cell performance and mass activity because of the good contact at the interface between the catalyst and the electrolyte membrane and low mass transfer resistance. The ultra-low catalyst loading electrode preparing by the sputtering method was a very effective method for reducing the catalyst amount and enhancing the mass activity.
\end{abstract}

Key Words : Liquid DMFC, Multi-layer Anode, Sputtering Method, Mass Activity

\section{Introduction}

The Liquid DMFC is expected as clean and useful power source for portable applications. However, the DMFC is not popular because of its high cost due to using a noble metal catalyst.

In order to overcome these problems, the catalyst utilization should be improved, and the amount of catalyst should be reduced. For the improvement of the catalyst utilization, Haugh et $a l^{1)}$ had reported that the electrode with a multi-layer structure improved the mass activity because the three-phase boundary was well formed. Liu et $a l^{2)}$ had reported that the multi-layer anode could be improved the mass activity. In our past sutudy, a threelayer anode showed the best performance compared to the single-layer, two-layer or four-layer anodes. For the reduction of the catalyst amount, we had obtained the catalyst with loading amount up to $0.04 \mathrm{mg} \mathrm{cm}^{-2}$ on the cathode. $^{4)}$

In this study, the effect of the catalyst loading preparing by sputtering method to obtain the superior catalyst utilization and the cell performance of ultra-low catalyst loading $\left(0.04 \mathrm{mg} \mathrm{cm}^{-2}\right)$ have been investigated.

\section{Experimental}

All anodes were prepared by sputtering Pt-Ru and spreading NCI or NC inks, which consisted of a 5 wt \% Nafion solution, carbon powder (Vulcan XC-72R), and isopropanol. ${ }^{1,5)}$ Two different kinds of catalyst support layers were formed in this study. The catalyst support layer NCI was made from a $5 \mathrm{wt} \%$ Nafion solution, carbon powder and isopropanol (the weight ratio of the three materials; N: C: I = 1: 1: 60). On the other hand, the catalyst support layer $\mathrm{NC}$ was made from a $5 \mathrm{wt} \%$ Nafion solution and carbon powder (the weight ratio of two materials; $\mathrm{N}: \mathrm{C}=1: 1)$. The anode preparation procedure is described as follows. Procedure one; the NCI ink or NC ink was spread on the carbon paper substrate (Toray
TGPH-090) and dried at $373 \mathrm{~K}$ for $40 \mathrm{~min}$. Procedure two; the Pt-Ru catalyst was loaded on this substrate with a catalyst support layer by the RF sputtering method.,7) These procedures were repeated one or three times and the multi-layer anode was prepared. We prepared five anodes, and these anodes were labeled as follows: (single layer anode with NCI catalyst support layer; NCI-1L, Single layer with NC catalyst support layer; NC-1L, three layers with NCI catalyst support layer; NCI-3L, three layers with $\mathrm{NC}$ catalyst support layer; NC-3L, three layers which have NCI catalyst support layer as the first layer and NCI catalyst support layer as the second and third layers; Composite -3L). The amount of the $\mathrm{Pt}-\mathrm{Ru}$ catalyst loading was $0.24 \mathrm{mg} \mathrm{cm}^{-2}$ or $0.04 \mathrm{mg} \mathrm{cm}^{-2}$ in all the anodes (the amount of loading catalyst in each layer of the $\mathrm{N}$ layer anode; 0.24 or $0.04 / \mathrm{N} \mathrm{mg} \mathrm{cm}^{-2}$ ).

The paste method anode and cathode were prepared by the same procedure of our past study. ${ }^{3)}$ The amount of catalyst loading was $2.0 \mathrm{mg} \mathrm{cm}^{-2}$ in paste method anode and $1.0 \mathrm{mg} \mathrm{cm}^{-2}$ in all cathodes.

The pretreated electrolyte membrane (Nafion 117), the anode and the cathode were assembled by hot-pressing them at $373 \mathrm{~K}$ and $10 \mathrm{MPa}$ for $2 \mathrm{~min}$ to ensure good contact among the cell components.

All the electrochemical measurements were performed at $338 \mathrm{~K}$. During the cell polarization curves studies, 1.0 M methanol was supplied at $1.25 \mathrm{~mL} \mathrm{~min}{ }^{-1}$ to the anode, and dry air was supplied at $62.5 \mathrm{~mL} \mathrm{~min}^{-1}$ to the cathode. When the anode impedance measurement or stripping voltammetry was performed, humidified hydrogen was supplied at $30 \mathrm{~mL} \min ^{-1}$ to the cathode that was used as the reference electrode. ${ }^{8)}$ The geometric areas of all the electrodes were $6.25 \mathrm{~cm}^{2}$.

\section{Results and Discussion}

Figure 1 shows the cell polarization curves. NC-1L showed a higher cell performance than NCI-1L as single 


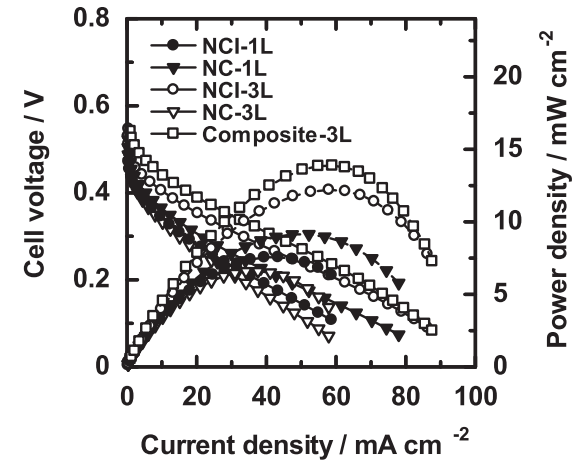

Fig. 1 Cell polarization curves for designed anodes. $\mathrm{C}_{\mathrm{MeOH}}$ $=1.0 \mathrm{M}$, Cell temperature $=353 \mathrm{~K}$.
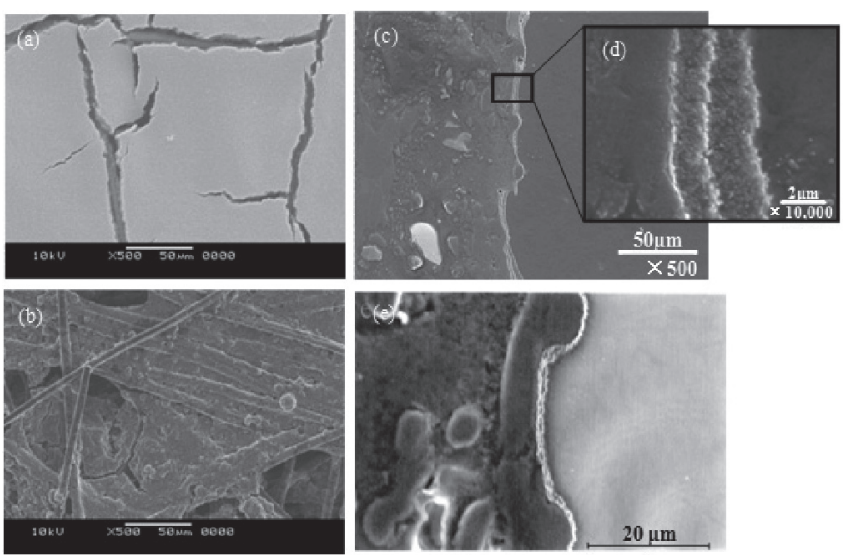

Fig. 2 The surface and cross section SEM images. Surface images: (a, b), cross section images: (c, d, e), electrodes: (a, c, d) NC, (b, e) NCI.

layer anodes. The multi-layer anode showed a higher cell performance than the single-layer anode. Composite3L showed the best performance in this figure.

In order to evaluate cell performance, the multi-layer anode after the impedance measurement was analyzed by SEM. Figure 2 shows SEM images of the surface and cross section. Pt-Ru particles were located on the white lines in the cross-section images (c, d, e), and the component of Pt-Ru was detected by EDX measurement. These images showed that the thin catalyst layer and catalyst support layer certainly formed a multi-layer structure. Furthermore, we estimated the catalyst support layer thicknesses and densities from the cross-section images and obtained the parameters listed in Table 1. According to this table, the NCI had a thin and porous structure and the NC had a thick and dense structure.

Figure 3 shows the anode Nyquist plots and Fig. 4 shows an equivalent circuit of anodic polarization. ${ }^{9}$ In the equivalent circuit, $\mathrm{R}_{\mathrm{m}}$ is the resistance of the membrane, $R_{1}$ and $C_{1}$ are parameters related to the interface, $\mathrm{R}_{2}$ and CPE are parameters related to the mass transfer, and $\mathrm{L}_{1}$ is related to $\mathrm{CO}_{\text {ads. }}$. The parameters obtained by the fitting are listed in Table 2.

In this study, we focused on the resistances $R_{1}$ and $R_{2}$. Since the NC had a dense and thick structure, the surface contact between the electrolyte and catalyst layers
Table 1 List of support layer thicknesses and densities.

\begin{tabular}{ccc}
\hline & Thickness $/ \mu \mathrm{m}$ & Density $/ \mathrm{g} \mathrm{cm}^{-3}$ \\
\hline $\mathrm{NC}$ & $1.8 \sim 2.0$ & $14.5 \sim 16.1$ \\
$\mathrm{NCI}$ & $0.5 \sim 0.8$ & $5.2 \sim 8.3$ \\
\hline
\end{tabular}

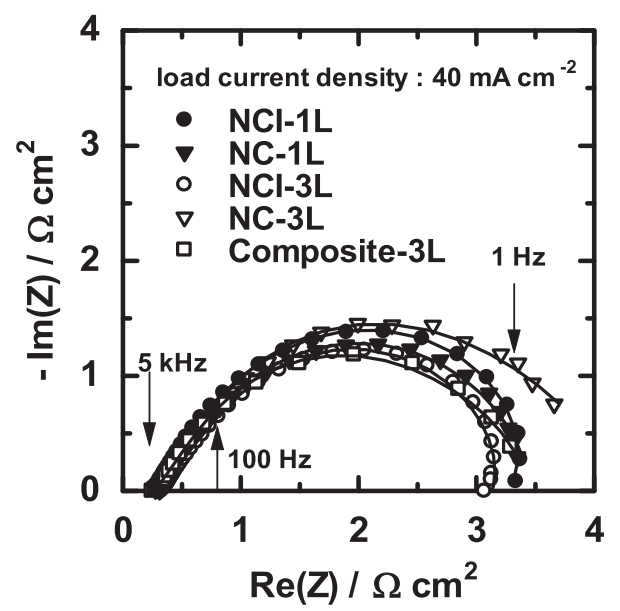

Fig. 3 Nyquist plots of multi-layer anodes at $40 \mathrm{~mA} \mathrm{~cm}^{-2}$. $\mathrm{C}_{\mathrm{MeOH}}=1.0 \mathrm{M}$, Cell temperature $=353 \mathrm{~K}$.

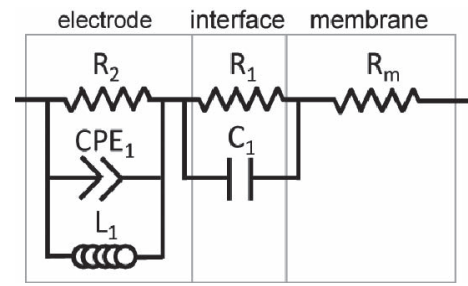

Fig. 4 Equivalent circuit of anodic polarization.

was improved. Consequently, NC-1L had a lower interface resistance $\mathrm{R}_{1}$. However, NC-3L showed the highest mass transfer resistance $R_{2}$ of all the anodes because the structural property of the NC support layer prevented the mass transfer. In contrast NCI layer showed lower mass transfer resistance. Finally, composite-3L had both advantages of the NC and NCI support layer. In other words, composite-3L had a good contact at the electrolyte-catalyst interface and a low mass transfer resistance. Therefore, composite-3L showed the best cell performance.

Figure 5 shows the mass activity in comparison to the paste method anode. The sputtering method anode showed a higher mass activity than the paste method anode. Since the three phase boundary was increased by the reduction of catalyst agglomeration due to reducing the catalyst amount in each layer, ${ }^{2)}$ the multi-layer anodes sowed a particularly higher mass activity than the paste method anode. Based on these results, the mass activity and cell performance were improved by using the designed catalyst support layer for the multi-layer anode.

In order to evaluate the cell performance of ultra-low catalyst loading, the multi-layer anode was prepared by sputtering or paste method. At that time, the amount of 


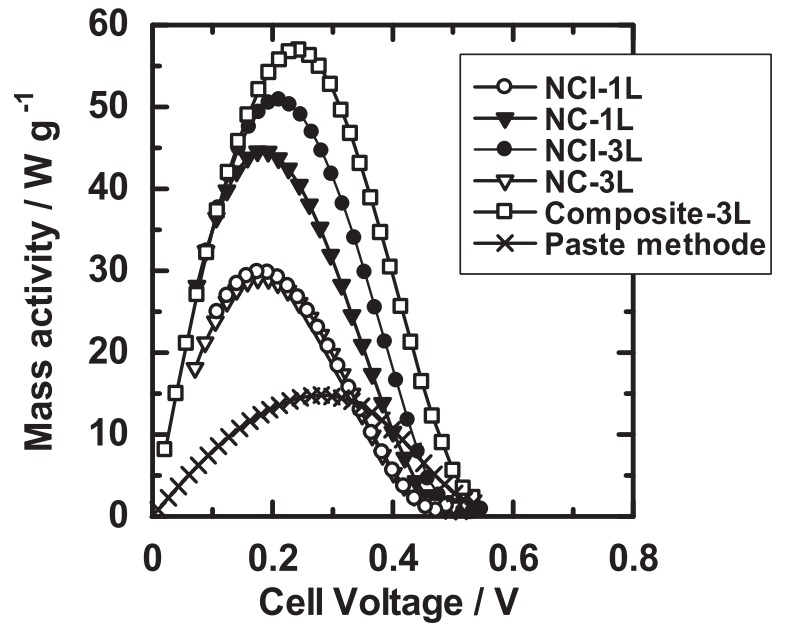

Fig. 5 Mass activity comparison of paste method and sputtering method.

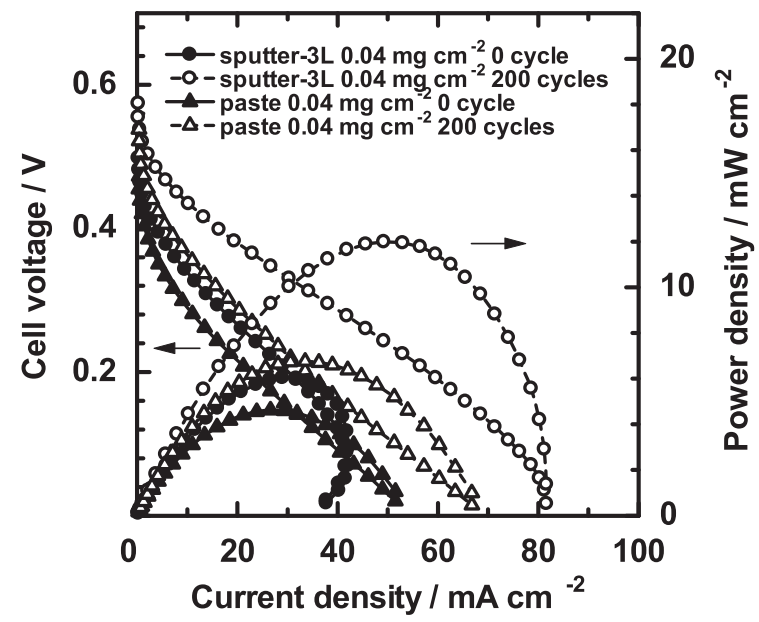

Fig. 6 Cell polarization curves for ultra-low catalyst loading anodes at initial condition and after $\mathrm{CV}$ condition.

net Pt-Ru was $0.04 \mathrm{mg} \mathrm{cm}^{-2}$ on each catalyst per layer. Figure 6 shows the cell polarization curves at the initial condition and after the potential cycling. The initial performance was almost the same between the paste method anode and sputtering method anode (paste: $52.3 \mathrm{~mA}$ $\mathrm{cm}^{-2}$, sputter-3L: $42.1 \mathrm{~mA} \mathrm{~cm}^{-2}$ ). On the other hands, the sputter-3L showed a dramatically high cell performance after the potential cycling (paste: $62.1 \mathrm{~mA} \mathrm{~cm}^{-2}$, sputter3L: $81.7 \mathrm{~mA} \mathrm{~cm}^{-2}$ ) and, the mass activity was also dramatically increased after the potential cycling (sputter3L: $300 \mathrm{~W} \mathrm{~g}^{-1}$ ). These performance changes might be considered as follows. $\mathrm{PtO}_{x}$ and $\mathrm{RuO}_{x}$ exist on the catalyst surface at the initial condition. These oxides led to the low activity and cell performance. However, these oxides were reduced after the potential cycling. Hence, the cell performance increased after the potential cycling. Moreover, the difference in the initial performance between the paste method anode and sputtering method anode was caused by their structures. The paste anode formed agglomerated $\mathrm{Pt}-\mathrm{Ru}$ and the distance between the $\mathrm{Pt}-\mathrm{Ru}$ particles was small. On the other hand, the sputter-3L anode formed the dispersed Pt-Ru and the distance between the Pt-Ru particles was significant far. Chakraboty et al. reported that oxide reduction smoothly occurs when $\mathrm{Pt}-\mathrm{H}$ or $\mathrm{Pt}-\mathrm{COH}_{x}$ exist near the oxides. ${ }^{10)}$ Therefore, the $\mathrm{PtO}_{x}$ and $\mathrm{RuO}_{x}$ reduction smoothly progressed on the paste anode and the initial performance was higher than that for the sputter-3L anode. In conclusion, the ultra-low catalyst loading by the sputtering method was a very effective method for the reducing catalyst amount and enhancement of the mass activity. However, it is necessary to carefully treat the initial condition, if we use the ultra-low catalyst loading by the sputtering method.

\section{Conclusion}

In this study, we succeeded in improving the mass activity by using designed catalyst support layer. A dense and thick catalyst support layer may lead to a low interface resistance. However, the much higher thickness and density led to a high mass transfer resistance and lower cell performance. The NC and NCI composite multi-layer anode showed the best cell performance due to its low mass transfer resistance and interface resistance.

The ultra-low catalyst loading anode made by the sputtering method was a very effective method for reducing the catalyst amount and enhancing the mass activity.

\section{References}

1) A. T. Haugh, R. E. White, J. W. Weidner, W. Huang, S. Shi, T. Stoner, and N. Rana, J. Electrochem. Soc., 149, A280 (2002).

2) C. Liu, T. Wang, F. Ye, Y. Fang, and X. Wang, Electrochem. Commun., 10, 255 (2008).

3) H. Saito, T. Nakashima, K. Nakase, and M. Sudoh, Jounal of Automation, Mobile Robotics \& Intelligent Systems, 3, 175 (2009).

4) M. Sudoh, K. Nakase, M. Tauchi, and K. Makino, ECS Trans., 11, 1397 (2007).

5) S. Y. Cha and W. M. Leeb, J. Electrochem. Soc., 146, 4055 (1999).

6) K. Makino, K. Furukawa, K. Okajima, and M. Sudoh, J. Power Sources, 166, 30 (2007).

7) A. Caillard, C. Coutanceau, P. Brault, J. Mathias, and J. M. Leger, J. Power Sources, 162, 66 (2006).

8) A. S. Arico, V. Baglio, A. D. Blasi, E. Modica, P. L. Antonucci, and V. Antonucci, J. Electroanal. Chem., 557, 167 (2003).

9) N. Y. Hsu, S. C. Yen, K. T. Jeng, and C. C. Chine, J. Power Sources, 161, 232 (2006).

10) D. Chakraboty, I. Chorkendorff, and T. Johannessen, J. Power Sources, 173, 110 (2007). 